\begin{tabular}{|c|c|c|}
\hline & Int.J.Curr.Microbiol.App.Sci (2016) 5(8): 760-768 & \\
\hline & International Journal of Current Microbiology and Applied Sciences & \\
\hline & ISSN: 2319-7706 Volume 5 Number 8 (2016) pp. 760-768 & \\
\hline $\begin{array}{l}\text { EXCELLENT } \\
\text { PUBLISHERS }\end{array}$ & & www ijemas.com \\
\hline
\end{tabular}

Original Research Article

http://dx.doi.org/10.20546/ijcmas.2016.508.085

\title{
A Comparative Study of the Occurrence of Cryptosporidium parvum oocysts found on Fresh Fruits and Vegetables Sold in Supermarkets and Open-aired Markets
}

\author{
Gehad T. El Sherbini ${ }^{1 *}$, Nancy Osman Hany Kamel ${ }^{1}$, \\ Morsy R. Geneedy ${ }^{2}$ and Ashraf G. Temsah ${ }^{3}$ \\ ${ }^{1}$ Department of Parasitology, Faculty of Medicine, October 6 University Cairo, Egypt \\ ${ }^{2}$ Department of Parasitology, Faculty of Medicine (Boys), Al Azhar University, Egypt \\ ${ }^{3}$ Department of Parasitology, Faculty of Medicine (Damietta), Al Azhar University Cairo, Egypt \\ *Corresponding author
}

\section{A B S T R A C T}

Keywords

Vegetables and

fruits,

Cryptosporidium

oocysts,

Food safety.

Article Info

Accepted:

28 June 2016

Available Online:

10 August 2016
Human cryptosporidiosis has emerged as an important gastrointestinal infection in the 1990s as a result of the ingestion of mainly contaminated water and to a lesser extent food stuffs containing the protozoan parasite, Cryptosporidium parvum. Fresh vegetables and fruits are an important part of a healthy diet and Consuming raw vegetables offers essential nutrients that one may not get when such vegetables are usually cooked. However, eating them raw may pose a great risk for transmissions of pathogens. Such risks may be influenced by the sources of the vegetables and washing techniques used. No previous surveys have been conducted to evaluate the prevalence of Cryptosporidium parvum contamination of vegetables in Egypt.The aim of the study was to compare the prevalence and diversity of cryptosporidium associated with vegetables and fruits sold at the two types of markets and compare effectiveness of various washing techniques. The result was Contamination of vegetables sold at the open-aired markets was about ten-times that of the supermarkets.

\section{Introduction}

In recent years, there has been an increase in the number of reported cases of food-borne illnesses linked to consuming fresh vegetables. The consumption of raw vegetables plays a major epidemiological role in the transmission of parasitic foodborne diseases. Food normally becomes a potential source of human infection by contamination, during production, collection, transport and preparation or during processing. The sources of zoonotic contamination are usually faeces, faecally contaminated soil or water (Slifko et al.,
2000; Daryani et al., 2008; Damen et al., 2007). Cryptosporidiosis is a nationally notifiable gastrointestinal illness caused by chlorine-tolerant protozoa of the genus Cryptosporidium. Cryptosporidiosis is a major public health problem in both developing and developed countries which caused by Cryptosporidium parvum. It is a most common parasite and can contaminate vegetables and fruits if these vegetables are irrigated with contaminated water which is defecated by both human and animal due to poor hygienic condition of the environment 
(McEvoy et al., 2003). Cryptosporidiosis has been incriminated as the most frequent microbial cause of diarrhoea accompanied by pain and abdominal colic and a noticeable loss of weight. Cattle have been seen to be an important source of zoonotic cryptosporidiosis since 1980's (Guerrant, 1997). Cryptosporidium infection is transmitted by the faecale-oral route and results from the ingestion of Cryptosporidium oocysts through faecally contaminated water or food or through direct person-to person or animal-to-person contact (Yoder et al., 2007).

Cryptosporidium has also become a wellknowncause of opportunistic infections among AIDS patients and of gastrointestinal disease outbreaks. Water and the food-chain have been reported as the main sources of outbreaks of diarrhea and other food-borne illnesses (Ali et al., 2006). Though cooking at high temperatures are expected to kill most pathogens, this method may not apply to fresh vegetables which are rather eaten raw. Freshly eaten vegetables are a major source of nutrients like vitamins (vitamin Bcomplex, vitamin-C, vitamin $\mathrm{A}$, and vitamin $\mathrm{K}$ ) and minerals (calcium, magnesium, potassium, iron, and beta-carotene) as well as dietary fibre. They protect the body against infectious diseases and serve as phytochemicals which function as antioxidants and anti-inflammatory agents reducing the risk of cardiovascular diseases, stroke and certain cancers (Ali et al., 2000; Ortega et al., 1997). They also help prevent constipation, hemorrhoids, and rectal fissures among others. Foodborne outbreaks of cryptosporidiosis have been reported since 1980s and have been identified from several commodities, mostly fruits, vegetables, shellfish (McEvory et al., 2007). These products are usually eaten raw and there is a concern that food may be a vehicle of transmission of Cryptosporidium. The main route of transmission of parasites diseases is the eating of raw vegetables without proper washing. Outbreaks of intestinal parasitic infections have been reported from developed and poor countries linked to raw vegetables and fruits (Ortega et al., 1997; Ortega et ak., 1993). Raw vegetables may be also contaminated with Cryptosporidium oocyts during the postharvest handling and processing. The degree of contamination of fresh vegetables mostly depends on several factors such as use of untreated waste water and water supplies contaminated with sewage for irrigation, and hygienic conditions of preparation in food service or home settings (Amoah et al., 2007; Beuchat, 2002; Carreno et al., 1999).

Egypt is an agricultural country where $80 \%$ people are associated with agriculture and almost all are involved with large or small scale vegetables farming. Huge amount of vegetables and fruits are produced countrywide every year. During harvesting and marketing, the uses of river, pond and contaminated sewage water are most common practices for irrigation of vegetables in Egypt. In addition, the poor hygienic condition of Egypt's environment which is mostly because of defecation by both animals and human can pollute water sources.

When such polluted water is used to irrigate raw vegetables and fruits can become contaminated with Cryptosporidium oocyts. In Egypt there are lots of markets countrywide where vegetables and fruits are sold and consumed. Therefore the main objective of this study is to determine the rate of contamination of vegetables and fruits with Cryptosporidium oocyts which will aware the people on the need to properly wash or cook vegetables prior to eating. 


\section{Materials and Methods}

\section{Study area and Sampling}

The present study was carried out during the period from September, 2014, to August, 2015. The study included 590vegetable samples, comprised of eleven types of vegetables and fruits: lettuce (80), watercress (116), parsley (88), green onion (100), onion (without leaves) (18) and leek (100), pepper (30), cabbages (10), carrot (20), fruits of tomato (12). The samples collected from farms, supermarkets, small markets and open aired markets. The openaired markets were selected because they are noted for supplying not just to consumers but retailers as well. The samples were collected in two rounds of purchases, two weeks apart. Cleanliness of the samples was ranked as unwashed (presence of dust or other particulate matter), washed (no visible form of dust) and washed and packaged.

\section{Sample Preparation}

Samples were transported to the laboratory in sterile plastic bags. They were divided into three groups and each group washed with tap water, saline (0.85\%) and phosphate buffered saline (PBS) (15). About $150 \mathrm{~g}$ of material was used for each vegetable except cabbage where one composite weighing about $400 \mathrm{~g}$ was used for each wash. Lettuces were separated into individual leaves whereas cabbages were divided in four. The samples were agitated vigorously (manually) in the respective liquids for about three minutes. The eluent was filtered through gauze and then dispensed into clean centrifuge tubes and centrifuged at $2000 \cdot \mathrm{g}$ for $30 \mathrm{~min}$. The supernatant was decanted and the residue was agitated gently in sucrose flotation medium of 1.18 specific gravity. Each tube was then topped to the brim with the flotation medium to form a meniscus. A cover slip was placed on the test tubes for about 3 mins and this was removed and placed on a clean glass slide and viewed under microscope for the presence of parasitic oocysts. Oocysts positive slide was allowed to air dry and stained using modified Ziehl-Neelsen technique (WHO, 1990; Brondson, 1984) by fixing the airdried slides in methanol for 2-3 minutes. The slide was flooded with cold carbolfuschin for 5-10 minutes and then with 1\% Hydrochloric-acid ethanol until color ceases to flow out and rinsed in tap water. Then the slide was counter stained with $0.25 \%$ methyl blue for 30 seconds, and rinse in tap water again and air dried.

\section{Identification of Cryptosporidum oocysts}

The slide was examined using a light microscope at 40 magnifications with oil immersion. The cryptosporidial oocysts appeared as bright rose pink spherules on a pale green background. Each oocysts present in each sample were enumerated were expressed as "many" (>three oocysts per high-power field; per low-power field); "moderate" (two oocysts/ high power field/ low power field); " "few" (one oocyst/field).

\section{Data Analysis}

With the use of EPI INFO 2002 (Dean, 1994), Chi square test was used to test for association between Cryptosporidum oocysts and factors such as type, nature, consumption and source of vegetables. OR values greater than unity denote association and less than unity denote that the factor may have a protective effect. $p_{-} 0.05$ was defined as significant. Prevalence was estimated by dividing the number of positive samples by the total number of samples.

Ethical approval was obtained from Ethics Committee of the University 


\section{Results and Discussion}

Of the 590 vegetables examined, 107 (18.1\%) were positive for Cryptosporidium oocysts. Ten varieties of vegetables were examined and all were positive for Cryptosporidium oocysts. Lettuce had the highest $(26.3 \%)$ contamination rate followed by Leek $(22 \%)$. There was no statistical significance (c2 $1 / 4$ 8.70; p $1 / 40.2747$ ) between occurrence of Cryptosporidium oocysts and types of vegetables examined (Table 1).

Table 2 shows the occurrence of Cryptosporidium oocysts in the different markets which were $224(37.9 \%)$ of the vegetables examined from open aired market was positive for Cryptosporidium oocysts followed by farms 165 (27.9\%) small market $130(22 \%)$, and $71(12 \%)$ from supermarkets. There was no statistical significance (c2 $1 / 4$ 0.22; $\mathrm{p}^{1 / 4} 0.8959$ between occurrence of Cryptosporidium oocysts and the markets in which the vegetables were sold.

Contamination was highest in leafy vegetables (37.4\%), followed by fruit vegetables $(35.5 \%)$ and root vegetables (27.1\%). There was no statistical significance (c2 1/4 1.79; p $1 / 4$ 0.4091) between occurrence of Cryptosporidium oocysts and the nature of vegetables examined (table 4).

The present study aimed at investigating some green vegetables that are frequently eaten raw for their possible contamination with Cryptosporidium oocysts in Cairo.

Table.1 Occurrence of Cryptosporidium oocysts and Types of Vegetables Examined

\begin{tabular}{|l|l|lc|}
\hline Sample ( $\mathrm{nl}=590)$ & No. examined & \multicolumn{2}{|c|}{ No. positive \% } \\
\hline Lettuce & 80 & 21 & 26.3 \\
Leek & 100 & 22 & 22.0 \\
Parsley & 88 & 18 & 20.5 \\
Green Onion & 100 & 19 & 19.0 \\
Cabbage & 10 & 1 & 10.0 \\
Watercress & 116 & 18 & 15.5 \\
Onion & 18 & 0 & 0.0 \\
Carrot & 20 & 4 & 20 \\
Pepper & 30 & 2 & 5.0 \\
Tomato & 12 & 2 & 16.7 \\
& & & \\
P>0.05 & & & \\
\hline
\end{tabular}

Table.2 Prevalence of Vegetables at Different Markets. Cryptosporidium oocysts Contamination of Examined Fresh

\begin{tabular}{|l|c|c|}
\hline \multirow{2}{*}{ Market $\mathrm{n}=590$} & \multicolumn{2}{|c|}{ Contamination } \\
\cline { 2 - 3 } & No. & $\%$ \\
\hline Farms & 165 & 27.9 \\
Supermarkets & 71 & 12.0 \\
Small markets & 130 & 22.0 \\
Open aired markets & 224 & 37.9 \\
\hline
\end{tabular}


Table.3 Seasonal Prevalence of Cryptosporidium Oocysts in Row Vegetable Plants

\begin{tabular}{|l|l|ll|}
\hline Year season & No examined & Positive & $\%$ \\
\hline Summer & 158 & 29 & 26.8 \\
Autumn & 122 & 22 & 17.3 \\
Winter & 108 & 18 & 16.6 \\
Spring & & 38 & 35.1 \\
\hline Total & 590 & 107 & 18.1 \\
\hline
\end{tabular}

$\mathrm{p}<0.05$ significant difference between different seasons

Table.4 Percentage of Contamination Sample with Cryptosporidium oocysts in Different Season in Examined Fresh Vegetables

\begin{tabular}{|l|l|l|l|l|l|l|l|l|l|l|}
\hline \multirow{2}{*}{ Sample } & \multicolumn{2}{l|}{ Summer } & \multicolumn{2}{l|}{ Autumn } & \multicolumn{2}{l|}{ Winter } & \multicolumn{2}{l|}{ Spring } & \multicolumn{2}{l|}{ Total } \\
\cline { 2 - 9 } & N0. & \% & No. & \% & No. & \% & No. & \% & No. & \% \\
\hline Leek & $\mathbf{6}$ & & $\mathbf{3}$ & & $\mathbf{1}$ & & $\mathbf{1 1}$ & & $\mathbf{2 1}$ & $\mathbf{1 9 . 6}$ \\
Lettuce & $\mathbf{7}$ & & $\mathbf{4}$ & & $\mathbf{1}$ & & $\mathbf{1 0}$ & & $\mathbf{2 2}$ & $\mathbf{2 0 . 5}$ \\
Parsley & $\mathbf{4}$ & & $\mathbf{4}$ & & $\mathbf{3}$ & & $\mathbf{3}$ & & $\mathbf{1 4}$ & $\mathbf{1 3 . 1}$ \\
Green Onion & $\mathbf{4}$ & & $\mathbf{3}$ & & $\mathbf{3}$ & & $\mathbf{9}$ & & $\mathbf{1 9}$ & $\mathbf{1 7 . 8}$ \\
Cabbage & $\mathbf{1}$ & & $\mathbf{0}$ & & $\mathbf{1}$ & & $\mathbf{0}$ & & $\mathbf{2}$ & $\mathbf{1 . 9}$ \\
Watercress & $\mathbf{3}$ & & $\mathbf{6}$ & & $\mathbf{5}$ & & $\mathbf{0}$ & & $\mathbf{1 4}$ & $\mathbf{1 3 . 1}$ \\
Carrot & $\mathbf{2}$ & $\mathbf{2}$ & & $\mathbf{2}$ & & $\mathbf{1}$ & & $\mathbf{7}$ & $\mathbf{6 . 5}$ \\
Pepper & $\mathbf{1}$ & & $\mathbf{0}$ & & $\mathbf{2}$ & & $\mathbf{2}$ & & $\mathbf{5}$ & $\mathbf{4 . 7}$ \\
Tomato & $\mathbf{1}$ & $\mathbf{0}$ & & $\mathbf{0}$ & & $\mathbf{2}$ & & $\mathbf{3}$ & $\mathbf{2 . 8}$ \\
Total & $\mathbf{2 9}$ & $\mathbf{2 2}$ & $\mathbf{1 8}$ & $\mathbf{3 8}$ & & $\mathbf{1 0 7}$ & $\mathbf{1 0 0}$ \\
\hline
\end{tabular}

Table.5 Occurrence of Cryptosporidium Oocysts and the Nature of Vegetables Examined

\begin{tabular}{|l|c|c|}
\hline Type & No & $\%$ \\
\hline Leafy vegetables & 40 & 37.4 \\
Fruit vegetables & 38 & 35.5 \\
Root vegetables & 29 & 27.1 \\
\cline { 2 - 3 } & 107 & 100 \\
\hline
\end{tabular}

Figure.1 Sample Collection Sites and Forms of Display

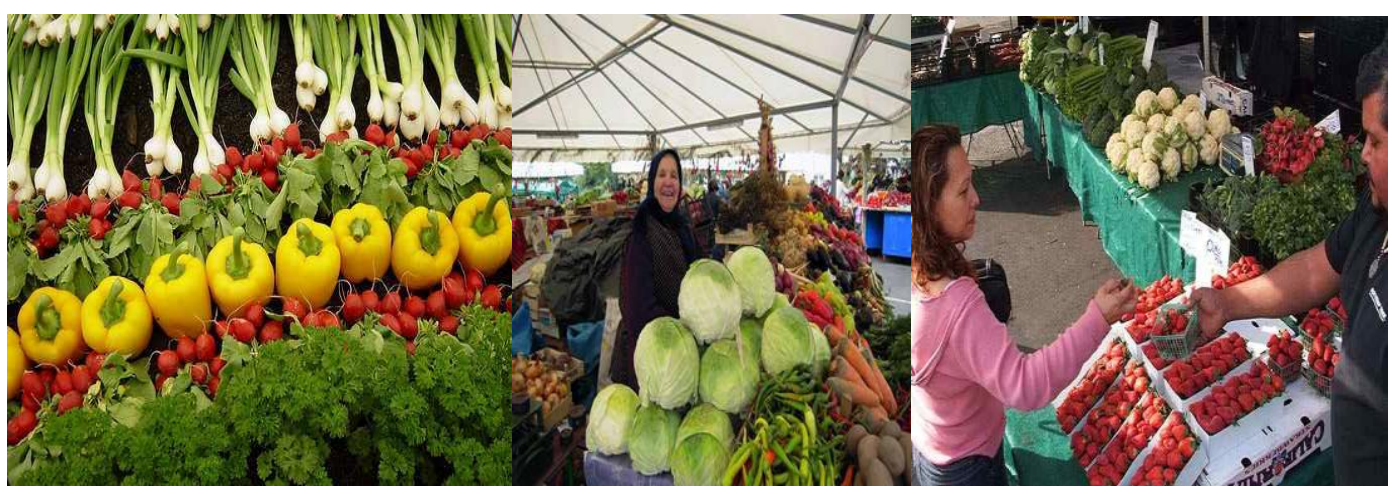

Fresh vegetables from different market (supermarket, small market and open air market) 
Fig.1 Modified Ziehl-Neelsen Stained Smear Showing Cryptospridium oocysts

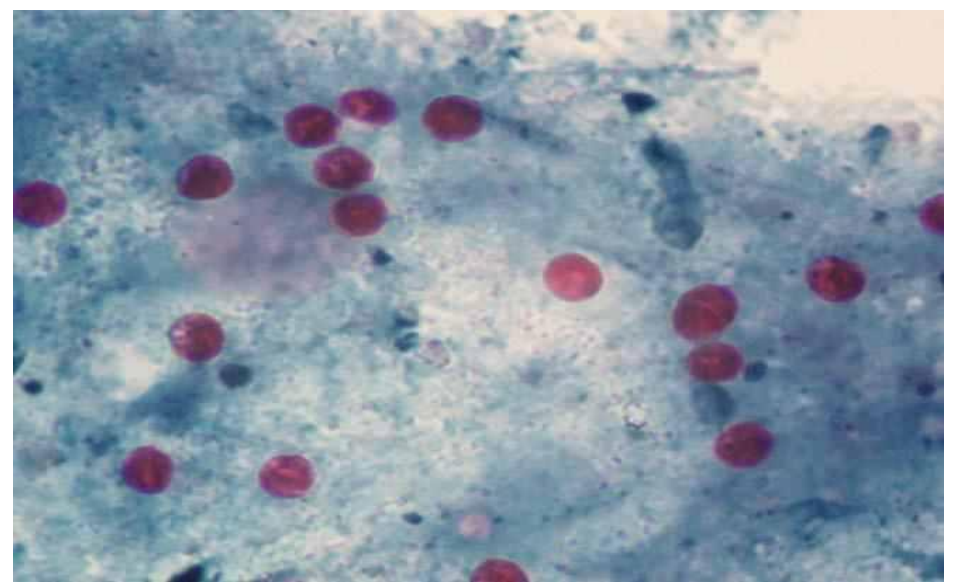

Responses from the retailers show that about $30 \%$ of the vegetables were gotten straight from farm while $70 \%$ were from middlemen who got them from farms and sold to retailers in the market before being sold to consumers. Likewise, vegetables were either washed in the farms and when brought to the market water from tap are used to constantly sprinkle on them to prevent from drying or they are washed in the market when brought in using tap water.

The $18.1 \%$ contamination rate of Cryptosporidium oocysts in this study is relatively high compared to the work of others (Monge et al., 1996). This may be due to the use of dirty water in washing the vegetables because as a routine, traders usually sprinkle vegetables with water to preventing them from drying. Water has been recognized as an important vehicle for the transmission of Cryptosporidium (Rose et al., 1990). The ubiquitous nature of this protozoan parasite and its potential for waterborne transmission is further facilitated by the perpetual infectivity of the oocysts, their small size $(3.5 \mathrm{e} 6.0 \mathrm{~mm})$ and their low sedimentation rate $(0.5 \mathrm{~mm} / \mathrm{s})(20)$. Surface water may become contaminated through the entry of human or animal faeces by either a direct or indirect route. Direct contamination of water may be due to the entry of faeces from agricultural run-off from adjacent farm animals or indirectly through accidental contamination from human sewage (Peng et al., 1997). Contact of the vegetables with soil may also play significant role in the contamination of the vegetables with Cryptosporidium oocysts as the vegetables were kept in dirty environment and in contact with soil. Also fertilization of horticultural crops, including vegetables, with manure from cattle and sheep, containing viable oocysts of Cryptosporidium, represents a significant risk to the contamination of vegetables (Moore et al., 2007).

The high occurrence of Cryptosporidium oocysts in lettuce maybe probably due to its broad leafy nature which may enhance it trapping higher number of oocysts from contaminated sources. Contamination of lettuce with food poisoning and foodborne pathogens may occur in the fields as a result of the introduction of the organisms from non-potable irrigation water or manure/compost, which still contains viable pathogens. There has been a number of lettuce associated food borne pathogens and the consumption of raw vegetables plays an important role in the transmission of parasitic contaminations (Anuar et al., 1977). A recent paper by researchers in USA 
demonstrated that Cryptosporidium oocysts were capable of strongly adhering to spinach plants after contact with contaminated water and in a variety of ways, it is mainly associated with the water used for irrigation. The use of sewage contaminated water for irrigation of vegetables is a common. The highest rate of contamination was detected in Green leafy vegetables $(37.4 \%)$. This could be due to the fact that the degree of contamination varies according to the shape and surface $f$ vegetables. Green leafy vegetables as lettuce, have uneven surfaces and makes Cryptospridium oocysts attached to the surface of the vegetable more easily, either in the farm or when washed with contaminated water. On the other hand, vegetables with smooth surface as leek and green onion had the least prevalence because its smooth surface reduces the rate of oocysts attachment. Some other studies have also demonstrated a higher contamination rate in leafy vegetables.

In conclusion, since vegetables are an important part of a healthy diet and can be consumed either raw or cooked, the findings from this research study is of great public health significance. The findings may have important implications for global food safety and emphasize the importance of raw vegetables in threatening public health by transmission of Cryptosporidium oocysts to humans in Egypt. The local health and environmental authorities should improvet he sanitary conditions in the areas where the vegetables are cultivated and consumed. Proper treatment of wastewater used for irrigation of vegetables should be implemented. There is also dire need for the improvement of sanitary facilities in our markets and vegetable vendors. Media programs should inform the consumers the potential health consequences of the consumption of raw vegetables, and the importance of proper washing and disinfecting of vegetables before consumption. In addition, they should focus on the necessity of good sanitation hygiene and risks of acquiring infection. More researches are needed to do surveys of contamination in green vegetables indifferent districts. Also, other surveys must be done in different governorates in Egypt. Also, other researches must be done to evaluate the level of contamination of irrigation water and soil in which green vegetables are cultivated. Different ways of disinfection of raw green vegetables must be improved.

\section{References}

Ali, M., Al-Bindi, Cornelius, S., Bello, Khalid El-Shewy, Slah, E., Abdulla. 2006. The prevalence of parasites in commonly used leafy vegetables in south western Saudi. Arabia, Saudi Med. J., vol. 27 (5), 613-616.

Amoah, P., Drechsel, P., Abaidoo, R. C., \& Klutse, A. 2007. Effectiveness of common and improved sanitary washing methods in selected cities of West Africa for the reduction of coliform bacteria and helminth eggs on vegetables. Tropical Med. Int. Health, 12 (Suppl.), S40-S50.

Anuar, A.K., Ramachandran, C.P. 1977. A study on theprevelance of soil transmitted helminths among lettuce leaves sold in local markets in penang, Malaysia. Med. J. Malaysia, 31: 262-265.

Beuchat, L.R. 2002. Ecological factors influencing survival and growth of human pathogens on raw fruits and vegetables. Microbes and Infection, 4, 413-423.

Simoes, M., Pisani, B., Marques, E. G. L., Prandi, M. A. G., Martini, M. H., Chiarini, P. F. T. 2001. Hygienicsanitary conditions of vegetables and 
water from kitchen gardens in the Municipality of Campinas, SP. Brazilian J. Microbiol., 32, 331-333.

Brondson, M.A. 1984. Rapid dimethyl modified acid fast stain of Cryptosporidium oocyst in stool specimens. J. Clin. Microbiol., 19: 952-5.

Carreno, R.A., Martin, D.D., \& Banta, J. R. 1999. Cryptosporidiosis is more closely related to the gregarines than coccidian as shown by phylogenetic analysis of apicomplexa parasites inferred using small-subunit ribosomal RNA gene sequences. Parasitol. Res., 85 (11), 899-904.

Damen, J.G., Banwat, E.B., Egah, D.Z., and Allanana, J.A. (2007).Parastic Contamination of Vegetables in Jos, Nigeria. Ann. Afr. Med., 6: 115-118.

Daryani, A., G.H. Ettehad, M. Sharif, L. Ghorbani and H. Ziaei, 2008. Prevalence of intestinal parasites in vegetables consumed in Ardabil, Iran. Food Control, 19: 790794.

Dean, A.G. 1994. A course in micro computer use for epidemiologist and others who count things using EPI INFO. Atlanta, USA; Centre for Disease control and prevention, Epidemiology program office.

Guerrant, R.L. 1997. An emerging highly infectious threat to our water supply. Emerging Infect. Dis., 3: 51-57.

McEvory, I.M., Moriaty, E.M., Ouffy, G., and Sheridan, J.J.T. 2003. The National Food Centre, Ashtown, Dubling 15. Ireland.

McEvoy, J.M., Moriaty, E.M., Duffy, G., \& Sheridan, J.J.T. 2003. The National Food Centre, Ashtown, Dubling 15, Ireland.

Mintz, E. D., Hudson-Wragg, M., Meshar, P., Carter, M. L., \&Hadler, J. L. 1993. Foodborne giardiasis in a corporated office setting. J. Infect. Dis., 167: 250-253.

Monge, R., Chinchilla, M., \& Reyes,L. 1996. Seasonality of parasites and intestinal bacteria in vegetables that are consumed raw in Costa Rica. Revista de Biologia Tropical.44, 369-375.

Moore, J.E., Millar, B. C., Kenny, F., Lowery, C., J., Xiao, J.R., et al. 2007. Detection of Cryptosporidium parvum in lettuce. International $J$. Food Sci. Technol., 42, 385- 393.

Ortega, Y. R., Roxas, C. R.., Gilman, R. H., Miller, N. J., Cabrera, L., and Taquiri, C. 1997. Isolation of Cryptosporidium parvum and Cyclospora cayetanensis from vegetables collected in markets of an endemic region in Peru. American J. Tropical Med. Hygiene, 57, 683-686.

Peng, M.M., Xiao, L., Freeman, A., R., Arrowood, M.J., Escalante, A.A., Weltman, A.C., et al. 1997. Genetic polymorphism among Cryptosporidium parvum isolate: evidence of two distinct human transmission cycles. Emerg. Infect. Dis., 3, 567-573.

Rose, J.B., \& Smith, H.V. 1990. Waterborne cryptosporidiosis. Parasitol., Todat, 6, 8-12.

Slifko T.R., Smith HV., Rose, J.B. 2000. Emerging parasite zoonosps associated with water and food. Int. J. Paracytol., 30 (12-13): 1379-1393.

Slifko, T. R., Smith, H. V., \& Rose, J. B. 2000. Emerging parasitezoonoses associated with water and fo Int. J. Parasitol., 1379- 1393.

Uga, S., Hao, N., T., V., Noda, S., Maji, K., Cong, L., Aoki, Y., A., et al. 2009. Parasite egg contamination of vegetables from a suburban market in Hanol, Vietnam. Nepal Med. college J., 11(2), 75- 78 . 
WHO (World Health Organization). 1990. Basic laboratory methods in medical parasitology. Geneva: World Health Organization.

Yoder, J.S. and Beach, M.J. 2007. Centres for Disease control and
prevention(CDC). Cryptosporidiosis surveillance- United States, 20032005, MMWR Surveillance Summit, 56(7).1-10.

\section{How to cite this article:}

Gehad T. El Sherbini, Nancy Osman Hany Kamel, Morsy R. Geneedy and Ashraf G. Temsah. 2016. A Comparative Study of the Occurrence of Cryptosporidium parvum oocysts found on Fresh Fruits and Vegetables Sold in Supermarkets and Open-aired Markets. Int.J.Curr.Microbiol.App.Sci. 5(8): 760-768. doi: http://dx.doi.org/10.20546/ijcmas.2016.508.085 